\title{
COMBLE: European Community of Integrative Blended Learning Experts
}

\author{
Christian Niemczik, Elke Brenstein, Margit Scholl
}

Zusammenfassung

Mit dem Comble-EU-Projekt entsteht ein neues innovatives Modell für die Anwendung von Blended Learning in verschiedenen Weiterbildungskontexten. Dafür werden mehrere Produkte für die Ebenen einer Weiterbildungsinstitution entwickelt. Basierend auf einem durch Anwendungspartner evaluierten Referenzmodell für Blended Learning soll ein Blended Learning Readiness Check entwickelt werden, der es Entscheidungsträgern ermöglicht zu erfahren, ob ihre Lerninstitution für die Implementation von Blended Learning bereit ist. Der Readiness Check wird als webbasiertes Tool erstellt und zusammen mit einer Beratung durch einen Experten angeboten. Auch auf der Ebene der Lehrenden soll ein europaweiter Austausch gefestigt werden. Hierzu wird eine europaweite »Methopedia« Community (www.methopedia.eu) aufgebaut, in der ähnlich wie bei Wikipedia gemeinsam Inhalte erstellt und gepflegt werden. Um Trainer in ihren methodischen und technologischen Fähigkeiten zu unterstützen wird ein Expertenkurs für Blended Learning entwickelt, der auf der Community-Seite zur Verfügung stehen wird. Der Kurs soll durch die Community frei veränderbar und damit für aktuelle Entwicklungen anpassbar sein. Auf der Ebene der Lernenden soll vor allem die Akzeptanz gefördert werden. Die European Blended Learning Driver's License soll Lernenden grundlegende IKT-Fähigkeiten vermitteln und sie in die Nutzung von Blended Learning Tools und Methoden einführen (Online-Konferenzen, VOIP, MindMaps, Application Sharing etc.), sodass lebensbegleitendes Lernen tatsächlich integraler Bestandteil ihrer lebenslangen Bildung werden kann.

\section{Abstract}

The COMBLE project defines new and innovative models for the use of Blended learning in different educational backgrounds (vocational training, enterprises, universities, public bodies). To use the potentials of Blended learning a European wiki-based community called Methopedia will be established. By contributing to the development of Blended learning COMBLE supports ICT relevant methods that are indispensable for lifelong learning in Europe. Moreover, COMBLE will address to management-level, learners and trainers at the same time.

We will develop a number of products - an applied reference model of Blended Learning, an expert course for trainers, and a European Blended Learning Driver's Licence within the overall frame of the Methopedia. These products support the development of a community for best practices and the use of Blended Learning to be used in all educational contexts. Moreover, the quality of education and training in Europe will be enhanced by improving innovative Blended Learning concepts.

COMBLE supports the successful implementation of Blended learning methods and strategies in the formal learning context of Vocational training, Continued Professional Development and Higher education systems. By working closely with application partners COMBLE develops practical, situated and innovative Blended Learning methods.
»We learn anywhere, anytime, anyplace; there are opportunities to learn all around us everyday. We learn in the home, office, on the road. Likewise, educational content can be shaped to fit all kinds of useful delivery media that is convenient, user-friendly, and (most important) serves the educational need of members without the content being shortchanged or trivialized «. (Smith, J., 2001)

\section{Pitfalls of Blended Learning}

Elliot Masie, in an Epic White Paper, answered the question »What is Blended Learning? « as follows: »It is the use of two or more distinct methods of training. This may include combinations such as: blending classroom instruction with online instruction, blending online instruction with access to a coach or faculty member, 
blending simulations with structured courses, blending on-the-job training with brown bag informal sessions, blending managerial coaching with e-learning activities.«

Blended learning has been found to be a viable and effective approach to deliver high-quality, up-to-date, on-demand learning solutions in the face of diminishing education budgets in higher education, further education or business education (Thorne, 2003). Blended learning makes up the »fastest growing use of technologies in learning - much faster then the development of online courses. «(Alvarez, 2005). However, experience has also shown that blended learning solutions often do not live up to the potential of the approach or fail to produce the intended results because administrators, instructors and learners are lacking the relevant technical, methodological or organisational knowledge and experience (McLaughlin, M. \& Mitra, D., 2001; Dirckinck-Holmfeld, 2002).

At the institutional/administrative level, administrators/managers may fail to realize the extent to which planning, implementing, evaluating, and maintaining blended learning solutions requires enforcing and supporting in-depth cultural and organisational change. To achieve sustainable high-quality learning outcomes, it is not enough to set up technical structures and educate trainers. Administrators/managers have to actively engage in change and acceptance management.

A successful blended learning strategy needs to take contextual factors such as the prevailing learning culture into account and address and deal with possible resistance to change on the part of all stakeholders (McPherson \& Nunes, 2006; Koper, Rusman \& Sloep, 2005; D’Antoni \& Mugridge, 2004).

At the instructional level, educators and trainers coming from a traditional teaching background often find it difficult to integrate ICT and expand their methodological repertoire to meaningfully combine learning activities during face-to-face, live e-learning, and selfpaced learning (Welker \& Berardino, 2005; Schlager, M. S., \& Fusco, J., 2004). They tend to resist changing established and proven instructional patterns unless they have experienced the possibilities of alternative methodologies for themselves. Often, the chosen »blend « merely consists of alternating traditional e-learning and instructor-led classroom components and does not accommodate the special needs of new forms of learning, e.g. self-organisation and online collaboration.
The choice of tools and methods is frequently driven by technological constraints rather than pedagogical requirements and learning activities are not integrated. The challenge is how to integrate virtual and face-toface learning, and how to integrate the idea of communities of practice, professional development and problem and project based learning (Barab, S. A. \& Duffy, T., 2000).

At the learner level, it has been shown that end users are not always equipped to handle the technical, psychological and organisational challenges of blended learning approaches. Learners, mainly accustomed to instructor-centred teaching methods in the classroom, do not acquire the necessary skills for self-organised, collaborative learning, which they need for distance learning (Sorensen \& Takle, 2002).

\section{Potential of Blended Learning}

Blended learning has been shown to be an effective tool in public as well as corporate educational settings. In the Thomson Job Impact Study (2003, http://www. delmarlearning.com/resources/job_impact_study_ whitepaper.pdf), researchers wanted to determine if blended learning increased the overall learning in a number of areas. The findings based on a survey of 128 participants from a number of corporate and academic organizations, including Lockheed-Martin, Utah State University, National Cash Register, and the University of Limerick in Limerick, Ireland support the effectiveness of blended learning. The results showed that the blended learning group "significantly« out-performed the traditional and e-learning group and they took less time to complete the real-world tasks than did the e-learning group. Overall, the blended learning classroom achieved a performance improvement of 30 percent.

Thus one of the most important advantages for business applications is its cost-effectiveness. Blended learning helps reduce expenditures related to traditional instructor-led training by reducing the amount of time needed for face-to-face instruction (Alvarez, 2005).

The benefits of using blended learning have been supported by research. The question remains how best to use the tools of blended learning to meet the goals of administrators, instructors and students. Therefore we create a model »Integrated Blended Learning «. The main principles are: 
Integrated Blended Learning - Key Characteristics

- Practice what you preach: It is important that instructors use the methods that they want students to work with during teaching or when interacting with each other

- Active learning: Instruction still largely follows a receptive paradigm, knowledge is often absorbed without actively engaging with the content. When learning steps are supplemented with activities where learners have to question, restructure or discuss the content, superior learning results will ensue.

- Blended Settings: In many blended learning settings, face-to-face meetings are held traditionally without the use of computers. When interacting with the computer is part of in-class instruction, instructors can model the use of technology and students can practice and receive support when encountering problems. Thus they are less likely to run into problems and be discouraged when working on their own.

- Open and Collaborative Learning Methods: Learning is more effective when results can be worked out and discussed with co-learners. Many methods used in seminar and workshop settings can supplement traditional teaching methods for better effect.

- Chaining learning activities: Often times with modular learning solutions, activities are performed in isolation. This can be in-effective and demotivating. When results from one learning activity are used in the next activity, learning becomes more meaningful and motivating.

- Accountability: It is important that students are held accountable for their learning results.

\section{IBL Success Factors}

- The introduction of Blended Learning is supported by administration/management

- The organisation/institution expects more than cost reduction from introducing IBL

- Blended Learning is introduced gradually

- Early Adopters use the approach and can demonstrate its functionalities and the effectiveness

- Trainers/Instructors are involved in the implementation from the beginning

- Instructors and learners have basic computer and internet skills and access to the required infrastructure

- Instructors and learners have baseline knowledge of blended learning tools, methods and skills: collaboration in online conferences, writing texts online, communicate via voip, brainstorming with mind maps in an application sharing etc.

- Instructors and learners are already used to activating and collaborative Methods

- Instructors and learners receive technical and didactical support

- Formative evaluation and quality control involves all stakeholders

\section{The COMBLE Project - Foster Blended Learning}

The overall objective for the COMBLE project funded by the EACEA Lifelong Learning ICT Programme is to improve the quality of Blended Learning in higher, further and business education by providing administrators, instructors and learners with knowledge, training, and consulting with regard to technical, didactic, organisational, and personal factors which may have an impact on the success of blended learning solutions. By including applications partners from three areas of education: higher education, vocational and further education as well as business education, practical considerations arising in different contexts are being explicitly considered.

The project is conducted by German, Danish, Polish and Estonian partners, taking primary responsibility for the following main objectives:

1. To assist administrators/managers in determining what is needed to implement successful learning outcomes in blended learning scenarios. To this effect, a Reference Model of Blended Learning Readiness is being developed, applied, and evaluated, lead by the German team at the University of Applied Sciences at Wildau, based on the theoretical and practical knowledge of the project partners and their application partners in all three areas of education and surveys and in-depth interviews with independent $\mathrm{BL}$ experts. Based on this reference model, the Blended Learning Readiness-Check, a procedure for the assessment of blended learning readiness at the level of the administrator, instructor and learner is being developed to support strategic planning, change management and the evaluation of BL scenarios at the institutional level.

2. To create a living community of Blended Learning Experts for instructors/trainers to share knowledge and experience regarding the implementation and evalu- 
ation of blended learning methodologies. Methopedia, a European wiki-based community site, is being set up by the German and Estonian partners from the University of Tartu for interactive access to Blended Learning methods, information on blended learning related ICT software and the Reference Model of Blended Learning Readiness, and the Blended Learning Readiness-Check.

3. To improve educator's/trainer's ICT and method competence for interactive and collaborative learning. To this end, a Blended Learning Train-the-Trainer Course will be set up, led by the Danish partner from the E-learning lab at Aalborg University, with special focus on the integration of face-to-face and virtual learning methods with special emphasis on the use of innovative didactical approaches to foster self-organised and collaborative learning.

4. To empower learners for using BL by providing them with a standardized baseline knowledge of blended learning tools, methods, and skills. A Blended Learning Course to be certified as »European blended learning driving licence « is being developed to familiarize learners with the basic technologies, tools and methods for Blended Learning by the Polish partner at the Maria Curie Sklodowska University in Lublin. The course is modular allowing for the substitution of alternative (localized) methods and technical implementations to be added later by members of the community.

\subsection{The Blended Learning Readiness Framework}

Blended Learning Readiness will be a model to check if an institution is ready for learning with new learning technologies and collaborative methods. It will support institutions, which want to implement blended learning taking into account organisational, technical, methodical and psychological aspects. Therefore we will create a Reference model of blended learning. It will be developed applied in order to identify success factors of blended learning implementation. The reference model will be based and evaluated on the theoretical and practical knowledge of the project partners, the contextualized knowledge and experience of associated Application Partners and surveys for further institutions. Each project partner will collaborate with application partners (see Section D, table of application partners) who currently use blended learning solutions, to assess the effectiveness of strategies, tools and methods and to get detailed context information. The Reference Model as well as the Blended Learning Readiness-Check will be available and editable via the Methopedia community.

The reference model will be publicly available to the Blended Learning expert community in wiki form. It will initially be based on the knowledge and experience of the project participants, but can later be continually refined and extended by the members of the Methopedia community, depending on their contextualized knowledge and experiences.

\section{Comble Products}

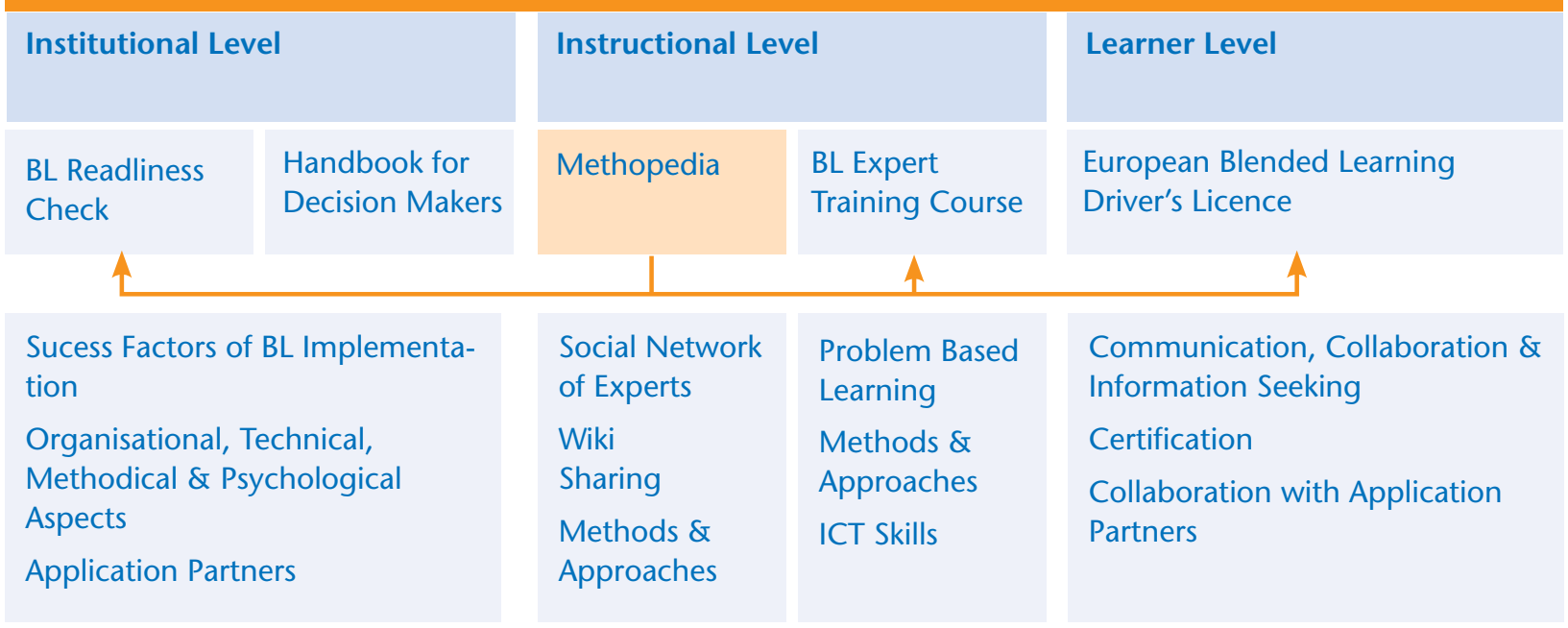

Image: The main outcomes of the COMBLE project. 


\subsection{Methopedia}

Learning technologies developed in recent years have a creative potential for improving quality of learning. However, this potential will only unfold if institutions implement suitable methodologies and learning cultures, and if instructors become able to integrate active learning by choosing fitting activities. As effects of assessments like Pisa show, learning institutions and educators want to benefit from the different learning cultures existing in Europe (Geller et al., 2007). To develop the Methopedia community for blended learning discussions and to share knowledge, methods and designs we wish to provide a wiki, as well as a connected social network. From the technical point of view the main product of the COMBLE project is therefore the development of Methopedia.

For trainers who already deal with blended learning related questions there have to be a platform for sharing detailed information's on methods. Therefore we want to build up a European wiki-based community called »Methopedia«, which will be set up by the German partners. The target group of Methopedia are mainly the managers and the trainers - first of all the trainers of the application partners and the connected networks.

To choose a suitable technology, we created a requirement profile by searching for similar projects and also by evaluating different wiki engines. There are already many resources about e-learning and blended learning on the Internet and we have already mentioned some of the interesting collections of activities (e. g. http://www. learn-line.nrw.de/angebote/methodensammlung/ liste.php). In order to gain an overview of some of the existing solutions, find inspiration and elicit some preliminary requirement we have also viewed and evaluated a number of other sites e. g.:

- http://www.uni-duesseldorf.de/ttt/?id=91\&kat=b15

- http://lehrerfortbildung-bw.de/kompetenzen/projektkompetenz/methoden_a_z/)

Our general impression was that many of the collections were quite static, without possibilities to rate, discuss, change or add new activities. From the outset we wanted Methopedia to be an active community/ network for sharing and creating; something which is also very important to engage partners and other practitioners in the process of developing a framework for shareable learning designs. Therefore, we have created the following tentative requirement list, which we expand on in the following sections:

\begin{tabular}{|l|l|}
\hline Need to have & Nice to have \\
\hline General: & Top contributors \\
\hline Open Source & Top topics \\
\hline Big Developer Community & New at Wiki \\
\hline Languages Interfaces & Visual overview \\
& (like concept \\
Wiki techniques: & map or mind \\
\hline XML-Interface (for export) & maps) \\
\hline ACL-Rights-Management & »Top rated« box \\
\hline Visually Customisable & \\
\hline Spam protection & \\
\hline Social support (connecting social software) & \\
\hline User functionality: & \\
\hline WYSIWYG & \\
\hline Template support (Templates for: Approa- & \\
ches, Methods, Course designs) & \\
\hline Page History & \\
\hline Conflict resolution & Possibility to comment/rate resources \\
\hline Social bookmaking & \\
\hline Discussions & \\
\hline
\end{tabular}

In order to identify the appropriate wiki we used »wiki matrix« (http://www.wikimatrix.org/) for a preevaluation. Based on our list we found that the best tool for our requirements is the MoinMoin wiki (http:// moinmoin.wikiwikiweb.de).

Apart from the technical requirements there are a number of socio-technical requirements that need to be addressed in order to create, sustain and nurture a living community. Although, we are aware that social interaction does not emerge automatically by providing people with certain functionalities, we focus, in this paper, on outlining some envisioned functionalities of Methopedia, rather than discussing in depth the 'social drivers' that need to be in place for a community to flourish.

According to (Wenger, 1998) communities of practice are characterised by: a joint enterprise, mutual engagement and a shared repertoire, whereas the idea of a network is characterised by weaker common or shared motives: »Network members share a marginal sense of commitment to each other, but are typically induced to contribute to the network as a means to increase their personal reputation and to collectively create a resource that has greater value than individual or group contribution and perspective (Zarb, 2006). Reward mechanisms for contribution to networks include peer review/ranking and other forms of both formal and informal contribution recognition.« (Dron \& Anderson 
2007, p. 2461). In this sense the social drivers may differ and change depending on the social architecture and composition of the participants. Also the drivers may vary for different user groups within the Methopediacontext.

\subsection{Blended Learning Driver's License}

The »European Blended Learning Drivers Licence« will be an online course including a certification. It will be developed to foster the learner's blended learning related ICT learning and collaboration competence. Trainers could use the course for their trainings, but also learners e. g. from (online) universities, European wide companies or members of the government. The course will be modular allowing the substitution of alternative methods and technical implementations. It will be downloadable as a SCORM package in Methopedia community. The course will be available in English and in the languages of the project partners. The Methopedia community will have the possibility to translate the course into further languages. Successful learners receive the »European Blended Learning Drivers Licence « certification by the University of Lublin, which guarantees the quality standards of the course and learners' competences in ICT and learning.

\subsection{The Blended Learning Expert Course}

The aim of the BL Expert Course is the development and testing a blended learning, certificated expert training course. The course will be based on the tailoring of »off-the-shelf products «, and an appropriation of Problem Based learning (PBL) approach. The development will take point of departure in a needs analysis of the application partners, and the tailoring of modules in relation to the Master program for professionals on ICT and Learning (MIL). Successful expert trainers receive a certificate issued by COMBLE Community and Aalborg University/Master in ICT and Learning, which guarantees the quality standards of the course and students' competences in ICT and learning. Furthermore the course will foster the integration of face-to-face methods and self-regulated as well as collaborative methods in order to enhance the learning ability of the learners. The course will be available in English and in the languages of the project partners. The course will be included as SCORM into the Methopedia community, which will be able to translate the course into further languages.

\section{Outcome and Benefits of the COMBLE Project}

The COMBLE project takes a holistic and integrative view of the blended learning in that it addresses issues related to the successful implementation of alternative forms of teaching and learning at three levels: the institutional, the instructional and the learner level. At the same time it addresses different domains by including technical, didactic, organisational and personal factors, which will be researched and represented in the reference model. Finally, by including applications partners from three areas of education: higher education, vocational and further education as well as business education it will be assured that practical considerations arising in different contexts are being considered.

Use of innovative didactical approaches: Equal emphasis will be placed on the use of open learning methods in classroom and distance learning in order to foster self-organised and collaborative learning. Based on the Integrated Blended Learning Approach, developed by the German partners, instructors will learn to design learning solutions where learning activities are not presented in isolation but interlaced and chained across instructional units. This has been shown to be a key factor for successful blended learning scenarios as it keeps learners active and motivated. It is also very effective as materials are re-used and recycled in different stages of the educational process. The principles will be documented on the Methodpedia site and applied in the Blended Learning Expert Course as well as the European Blended Learning Drivers Licence. 


\section{Literature}

Alvarez, S. (2005). Blended learning solutions. In: Encyclopedia of Education Technology, ed. B. Hoffman. http://coe.sdsu.edu/eet/ articles/blendedlearning/index.htm.

Barab, S. A./Duffy, T. (2000): From practice fields to communities of practice. In: Jonassen, D./Land, S. M. (Eds.): Theoretical Foundations of Learning Environments (pp. 25-56). Mahwah, NJ: Lawrence Erlbaum Associates.

D'Antoni, S./Mugridge, I. (2004): Virtual universities and transnational education: Policy issues: What are they? And whose are they? Internet discussion forum 19 January - 20 February, IIEP/ United Nations Educational, Scientific and Cultural Organisation. Retrieved May 20, 2005, from http://www.unesco.org/iiep/virtualuniversity/forums2.php?queryforums_id=1\&querychapter=1

Dirckinck-Holmfeld, L. (2002): Designing Virtual Learning Environments Based on Problem Oriented Project Pedagogy. In: Dirckinck-Holmfeld, L./Fibiger, B.: Learning in Virtual Environments Frederiksberg C, Samfundslitteratur Press.

Dron, J./Anderson, T. (2007): Collectives, Networks and Groups in Social Software for E-Learning. In: Richards, G. (Ed.): World Conference on E-Learning in Corporate, Government, Healthcare, and Higher Education 2007, AACE, Quebec City, Canada, pp. 2460-2467.

Koper, E. J. R./Rusman, E./Sloep, P. (2005): Effective Learning Networks. Lifelong learning in Europe, 1, pp. 18-27.

McLaughlin, M., \& D. Mitra. (2001). Moving deeper and broader with theory-based change Journal of Educational Change , 3(1), pp. 301-323.

McPherson, M. A./Nunes, J. M. (2006): Organisational Issues for e-Learning: Critical Success Factors as Identified by HE Practitioners. International Journal for Educational Management, 20(7), pp. 542-558.

Schlager, M. S./Fusco, J. (2004): Teacher professional development, technology, and communities of practice: Are we putting the cart before the horse? In S. Barab, R. Kling, and J. Gray (Eds.), Designing Virtual Communities in the Service of Learning. Cambridge University Press.

Scholl, M./Dressler, T./Niemczik, Ch./Brenstein, E. (2006): eBusiness + eGovernment + eLearning: Technologiegestützter After Sales Services in KMU, Workshop, 3. Fernausbildungskongress der Bundeswehr, Helmut-Schmidt-Universität, Universität der Bundeswehr, Hamburg, September 2006

Sorensen, E. K./Takle, E. S. (2002): Collaborative knowledge building in web-based learning: assessing the quality of dialogue. The International Journal on E-Learning 1, No.1, pp. 28-32.

Thorne, K. (2003). Blended Learning: How to Integrate Online and Traditional Learning. London: Kogan Page Limited.

Welker, J./Berardino, L. (2005): Blended Learning: Understanding the Middle Ground between Traditional Classroom and Fully Online Instruction. Journal of Educational Technology Systems. vol. 34. no. 1:33-55.

Wenger, E. (1998): Communities of Practice - Learning, Meaning, and Identity, Cambridge University Press, New York.

\section{Authors}

Christian Niemczik (Projektmitarbeiter)

Prof. Dr. Margit Scholl

Technische Fachhochschule Wildau

Fachbereich Wirtschaft, Verwaltung und Recht

christian.niemczik@sudile.com

margit.scholl@tfh-wildau.de

\section{Dr. Elke Brenstein}

Learning \& Development Consultant, Trainer \& Coach Dotconex

Elke.Brenstein@dotconex.com 